This item was submitted to Loughborough's Research Repository by the author.

Items in Figshare are protected by copyright, with all rights reserved, unless otherwise indicated.

\title{
Exploring the emergence of the subject in power: infant geographies
}

PLEASE CITE THE PUBLISHED VERSION

http://dx.doi.org/10.1068/d12711

PUBLISHER

(C) Pion

VERSION

AM (Accepted Manuscript)

LICENCE

CC BY-NC-ND 4.0

REPOSITORY RECORD

Holt, Louise. 2019. "Exploring the Emergence of the Subject in Power: Infant Geographies". figshare. https://hdl.handle.net/2134/13084. 


\title{
Exploring the emergence of the subject in power: infant geographies
}

\author{
Louise Holt \\ Department of Geography \\ Loughborough University \\ Loughborough \\ Leicestershire \\ LE11 3TU \\ l.holt@lboro.ac.uk
}

\section{Acknowledgements}

Thanks to my children, who inspired this paper when they were babies. I would also like to express grateful thanks to the following people whose insightful comments have enhanced the paper: Matej Blazek, Sophie Bowlby, Sarah Holloway, Peter Kraftl, Melissa Stepney, Christiana Toren and two anonymous referees. Thanks also to the editors of Society and Space, particularly Natalie Oswin. I take responsibility for any mistakes or inaccuracies. 


\section{Exploring the emergence of the subject in power: infant geographies}

\section{Abstract}

Following Butler's (2004) argument that understanding the operations of power requires an examination of the contexts of 'infants' emergence', this paper explores the potential for infant geographies. Butler $(1997,2004)$ points to the importance of infancy to subjection, the formation of psyches and the 'fiction' of an interior or socially anterior self. Attention to infants' everyday geographies therefore has the potential to unravel how individuals are subjected; how power becomes an embodied part of individuals' subjective identities, operating creatively to produce subjects with agency, and, at the same time, limiting and circumscribing appropriate subjectivities. A critical reflection on Butler suggests a need to focus upon how subjection occurs in specific material spaces, and the role of a host of human and non-human others to process of subjection. Also pertinent is a fuller exploration of how diversities of kinship and non-kinship social relations might lead to other constellations of power in the subjection of infants. How the geographies of infants can be operationalized methodologically and epistemologically is also explored. The paper has broader resonance to issues of subjection, how embodied inequalities are reproduced and/or transformed, questions of agency, and concerns to deconstruct an autonomous, thinking, rational, human subject within human geography - reconfiguring individuals as constituted within emotional and psychic interdependency.

\section{Key words:}

Infants, babies, subjection, subjectivation, ethnography, Judith Butler, psychoanalytical geographies, emotion, affect, agency, subject 


\section{Introduction}

'Part of rethinking where and how the human comes into being will involve a rethinking of both the social and psychic landscapes of an infant's emergence' (Butler, 2004:14).

By playing close, critical attention to Butler's works The Psychic Life of Power (1997a) and Undoing Gender (2004), which demonstrate how infancy is crucial to the formation of subjects who psychically incorporate powerful norms, this paper outlines the merits of more fully acknowledging the everyday geographies of infants. These have been largely overlooked in human geography'. Exploring geographies of infants can contribute to reconfiguring notions of the subject and agency (Lorimer, 2007; Parr and Davidson, 2011; Ruddick, 2007a,b) by emphasising how enduring power inequalities are (re)produced via individual (and collective) identities and deconstructing the autonomous subject/agent; enduring questions within strands of human geography. More specifically, drawing upon Butler (1997a, 2004), I argue that geographical studies of infancy can illuminate the psychic operation of subjection (subjectivation); how power operates to creatively constitute 'individuals', into being and simultaneously subject people within frameworks of (classed, sexualised, gendered, racialised, (dis)ablediii) norms, also providing the potential for these contexts of power to be transformed.

It is important to pay attention to these issues in youngest childhood, since infancy is a specifically dynamic phase of growth and development - biologically, socially, psychically. Butler's (1997a, 2004) attention to infancy highlights the ontological relationality of the development of subjects who are produced within power but capable of transforming power. The importance of infancy as a period of sociopsychic development has also been heralded in much psychoanalytical geography (Philo and Parr, 2003; Pile, 1996; Sibley, 1995) and studies of children's socialisation 
(McDowell, 2006). Classed, racialized, gendered, and sexualized norms begin to be embodied during this period of our lives. Norms which are psychically incorporated (in infancy) are argued to be difficult to challenge, as they are pre-discursive and reproduced in beyond-conscious ways (Bourdieu and Thompson, 1991; Pile, 1996). Geographers, crucially, then, need to engage with the geographies of infants to provide insights into how enduring inequalities are reproduced (or can be transformed), via embodied identities.

Although infancy is a specifically dynamic phase of the life-course, it is not unique; our mind-bodies continue to change throughout our lives (Shilling, 2003). The intersubjectivity and interdependency inherent in the construction of subject/agents in infancy is an enduring part of (adult) selves. Butler (2004: 24) claims that: "infancy constitutes a necessary dependency, one which we never leave behind". Indeed, the vulnerability, and relationality of infants is merely a particularly stark expression of the intersubjectivity and interdependence of all human beings. Therefore, examining the everyday geographies of infants can contribute to endeavours to deconstruct the autonomous agent and replace it with an inherently relational, intersubjective / interdependent subject within human geography, particularly within nonrepresentational theory and geographies of emotion and affect (see for overviews Anderson and Henderson, 2010; Pile, 2009). Furthermore, geographies of infants can enable insights into how agency emerges within these inter-subjective processes of subjection.

Despite Butler's many contributions, these are subject to two critiques in this paper. First, I argue for more explicit considerations of a host of infant-other (including nonhuman other) relations, including a greater attention to the maternal, which arguably theorises inter-dependency relatively positively and places a greater emphasis on emotional interdependence and contiguity. Second, I propose that empirical studies 
of the socio-spatial contexts of the subjection of infants could take Butler's theoretical accounts forward. In the final section, drawing upon existing studies in geography and beyond, I then point to some possible methodological and epistemological ways to operationalize empirical studies of infant geographies.

\section{Infancy, interdependency and subjection}

Butler's Foucauldian theorisations on the psychic life of power ${ }^{\text {iv }}(1997 a, 2004)$ seek to understand processes of subjection: how and why the constitution of identities occurs within specific frameworks of power, such that power creatively brings subjects into being within specific frameworks of (gendered/sexed - but also classed, racialised, (dis)abled) power. Subjection acts in various, intersecting, ways. First, subjection is done by the subject to itself. People willingly, although often in ways that are not conscious, situate themselves within frameworks of power (which are however, never complete and always reiterated and worked anew). This is not (only) an external enactment of power over individuals, but a creative play of power within the constitution of the subject, which simultaneously limits the person's possibilities and brings the subject into being. Second, subjection allows people to enact agency, permitting them to 'exceed' (not fully escape) the existing exegesis of power (Butler, 1997a). Thomas (2007) claims that Butler's theories of the psychic life of power have received less attention within geography than has performativity. There is, however, a bourgeoning interest in this strand of Butler's work (see for instance, Bondi, 2005; Gallagher, 2011; M. Rose, 2002).

In the Psychic Life of Power, Butler's (1997a) analysis draws upon a variety of philosophical and psychoanalytical approaches to subjection, from Hegel to Freud, Nietzsche, Lacan, Foucault and Althusser. Despite this diversity of perspectives, two key themes emerge of relevance to this paper. First, Butler implicitly cites infancy as pivotal to the formation of the subject in subjection. Second, and connected, Butler 
emphasises that subjection is relational, and occurs within the context of emotionallyphysically-psychically interdependent relationships. Both of these themes are taken forward in Undoing Gender (Butler, 2004).

Butler (1997a) posits infancy as a crucial phase in the development of the subject within subjection. She critically (and somewhat paradoxically, given Foucault's (1978) take on psychoanalysis), synthesises (post-)Freudian psychoanalytical theories with Foucauldian accounts of subjection to explore how the subject is formed via a central prohibition of certain forms of sexuality in earliest childhood. In Undoing Gender, Butler (2004) broaches the topic of the incest taboo and the Oedipus complex, Freud's concept of a fantasised sexual love of a (male) child for his mother and the associated death drive for the father. (Freud is less clear about the fantasised love between daughters, fathers and mothers). Butler (2004) highlights how the (concept of) the Oedipus complex reinforces heterosexual and forecloses homosexual love, with heterosexual desire becoming a necessary element of gender. Foreclosure goes beyond repression, in that the possibility of these loves has never been consciously acknowledged and these loves are therefore never fully disavowed. Instead, they become incorporated into the 'ego' (or reflexive self) as a "melancholic incorporation" (Butler, 1997a: 134). The melancholia (unresolved grief) of the disavowed love hovers at the edge of consciousness, unsettling the subject. The melancholia implies the provisional nature of subjectivities: "it exposes the fault lines in its own tenuous foundations" (Butler, 1997a: 169). Subjection is therefore never total or complete; it is always provisional and on-going. This, then, suggests the possibility of performing subjectivities otherwise. Thus, melancholia can be a beginning-point for transforming the existing exegeses of power (cf. Werner, 2006).

This central prohibition is pivotal to the formation of "the critical agency commonly called conscience" (Butler, 1997a: 181) or the 'fiction' of an interior, socially anterior 
self. Butler (1997a: 103) states that "in Freud's view the formation of conscience enacts an attachment to prohibition which founds the subject in its reflexivity". In Foucault "the very process of subject formation ... requires a ... founding prohibition that prohibits desire but itself becomes a focus of desire, then a subject is formed through the prohibition of a sexuality, a prohibition that at the same time forms this sexuality - and the subject who is said to bear it'. Therefore, these central prohibitions, which begin in infancy, create the sense of an interior self, psyche or individual. Like Nast (2000), Pile (1996), Wilton (2003) and the majority of psychoanalytical geographers (cf. Callard, 2003), Butler (1997a) critiques the idea of an interior or socially anterior psyche (although she does emphasise a socially resistive interiority in the form of the unconscious, as discussed below).

Butler (1997a) considers the importance of infancy to subjection. However, these foreclosures are carried throughout life as they are foundational to the construction of the psyche and the fiction of the autonomous self. Importantly, in common with the majority of psychoanalytically informed geographers (Nast, 2000; Pile, 1996; Wilton, 2003), Butler (2004: 158) departs from Freud and Lacan in viewing the Mother and Father (phallus and so on) not as pre-social, universal symbolic categories, but as "contingent social practice[s]". Butler (2004) begins to trace the genealogy of these categories to demonstrate the socio-historical specificity of their emergence. Therefore, she suggests that psychic relations (and how they are theorised) reflect and (re)produce the dominant frameworks of heterosexist and patriarchal power. These psychic relations are thus open to challenge and transformation. Since they are foundation to the constitution of the psyche and the notion of 'self', it seems likely that once embodied, these relations are difficult (although not impossible) to transform. Butler (2004) also seeks to explore more diverse forms of kinship than are expressed in the Oedipus complex (Butler, 2000), although she does not fully envisage how these might be played out in infancy. It would be pertinent to explore 
more fully how figuring, living and conceptualising, kinship beyond Oedipus might influence the socio-psychic relations and subjection of infants.

The second theme of relevance to this paper in Psychic Life of Power which is more fully developed in Undoing Gender, is that subjection is always relational, occurring within the context of physically and emotionally interdependent psycho-social relationships. Butler (2004) contends that the need for socio-psychic recognition underpins relationships of subjection. Here, then, Butler, unravels why people have: "a passionate attachment to subjection" (Butler, 1997a: 105).

Crucially, Butler (2004) points to the emergence of the subject in infancy as central to subjection. Infants require physical and emotional nurturing to thrive. This nurturing has a double-edge in (re)producing subjection. The dependency and fragility of infants is simply the clearest expression of that in which all individuals are constituted (see also Harrison, 2008). This foundational dependency is what exposes people to subjection: “...we are, from the start, and even prior to individuation itself, and by virtue of our embodiment, given over to another" (Butler, 2004: 23). Butler (2004) argues, from a variety of philosophical and psychoanalytical perspectives from Hegel to Jessica Benjamin, that requiring emotional recognition compels individuals to (unconsciously) accept psychic existence through subjection. Hence emotional and physical intersubjectivity and interdependence are at the heart of subjection and the formation of a sense of self; a pertinent point for geographies of emotion and affect.

Given the importance of infancy to subjection, Butler (2004) suggests that changing the conditions of the infant's emergence can transform the norms by which individuals are subjected. Despite this claim, she does not fully investigate the possibilities of other types of kinship and social relations to transforming the normative power contexts in which infants can be situated and subjected. Further, 
given her philosophical focus and her lack of empirical investigation of everyday lives, Butler does not explore how individuals might be differently subjected in various socio-spatial contexts along a variety of intersecting 'axes of power relations' (Butler, 1990), including class, ethnicity, race, religion and (dis)ability, as well as gender and sexuality. Finally, the possibility of other types of kinship relations begs the questions of from where does the spark of something compelling change arise? Where has the impulse come from to change the psychic conditions of infants' emergence and to enact power otherwise on and within the subject?

\subsection{Imminent agency, and the whence of agency}

There has been much debate about where such post-Foucauldian approaches to subjection, as Butler's, leave the concept of agency (Nelson, 1999). Does destabilising a sovereign subject-agent and demonstrating that it is (re)produced via power and within meshes of inter-dependent and inter-subjective relations jettison any idea of conscious, purposeful agency (McNay, 1999)? Partially in response to such critiques, Undoing Gender more fully addresses questions of agency and the possibility of social transformation, or of collectively "undo[ing] restrictively normative conceptions of sexual and gendered life" (Butler, 2004: 1).

Acceptable norms of personhood by which subjects are positioned are provisional. Subjection is always on-going, reiterated and performed anew in every enactment (Butler, 1997a: 94), rather than being fixed, and is consequently open to transformation. Thus, norms are socio-spatially shifting and contextual, rather than fixed (Holt et al., forthcoming; Hansen and Philo, 2007). Further, the power which enables a subject to come into being operates differently when wielded by the subject as agency (Butler, 1997a). Here, Butler is exploring the creative potential of power, along with its dominating effects. Butler (1997a, 2004) allows for political agency to exist; an agency which emerges from conditions of power but is not fully 
constrained by them. She points to the double-edge of the subject, which necessitates its own subordination in its formation, but which then can enact power as agency.

Although clearly conceiving of agency, Butler dismantles the sovereign agent and replaces it with a subject in which agency is imminent. On the one hand, Butler (1997a) is clear about the distinction between the subject, the individual and agency. She claims the subject is not synonymous with the individual, rather the subject: "ought to be designated as a linguistic category, a place-holder, a structure in formation...the subject is the linguistic occasion for the individual to achieve and reproduce intelligibility, the linguistic condition of its existence and agency" (Butler, 1997a: 10-11). On the other hand, in the way that these terms are used, the distinction between the subject, individual and agent are not systematically maintained. For instance, she discusses the "agency of the subject" (p. 12). It is unclear how a linguistic category could wield agency (although it is evident that occupying an appropriate linguistic category can provide social legitimacy).

It is perhaps more pertinent to conceive of an embodied person, subjected via subjection, who can enact agency. Although it is useful to separate out the subject, embodied person and agency in theorising processes of subjection, it is difficult to maintain this distinction in substantive accounts. Butler is not faced with this problem; her empirical accounts focus on literary and media analysis, not primary research with people. Her conception of agency is limited by this focus (McNay, 2004). It is possible to work with the insightful perspectives Butler offers and 'take them elsewhere' via empirical accounts (Gregson and G.Rose, 2000). In Butler's work, the distinction between the subject as a linguist category and the lived individual reproduces a dichotomy between the social and the discursive which would apparently prioritise the discursive over the corporeal, as she posits the subject as 
preceding the agent (McNay, 2004). It is ironic that she is critiqued on these grounds as her key achievement, arguably, has been inspiring a sensitivity to intersections of social readings and lived experiences of bodies.

A question that remains unresolved in Butler's work, is from where does a resistant agency arise which is able to contest and transform dominant power relations? Butler (1997) suggests the unconscious as a source of agency. Although not fully outside of the reaches of power:

“... the unconscious only and always resists normalisation ... a certain unharnessed and unsocialised remainder is thereby produced which contests the appearance of the law-abiding citizen" (Butler, 1997a: 88). "This will not make the unconscious outside of power, but rather something like the unconscious of power itself..." (p.104).

Despite resisting the notion of a pre-social interiority, Butler ultimately sites resistance (and agency) within the deepest interior of the unconscious (Callard, 2003; Pile, 1997). Although problematic, it is useful to focus upon power's creative potential to enact the subject (with agency) into being (Hollway, 2006). It is important to think-through how regimes of normalising power can be transformed in conscious, deliberate ways, as well as through unconscious practices, such as slippage, or inappropriate identity performances (Butler, 1997b). It is therefore necessary to consider where a spark of something might emerge that compels a subject to perform power in different ways, without recourse to a socially anterior self.

This implicit situating of agency within the unconscious highlights the importance of specific contexts of infants' emergence to social transformation, since: “...the experiences of early childhood are generally accepted to be critical" (Pile, 1996: 7) to the formation of the unconscious. Sensitivity to the socio-spatial contexts of infants' 
emergence might therefore facilitate an exploration of how the spark that seeks to resist the existing performances of power emerges, without recourse to a sovereign agent. This also suggests the importance of non-patriarchal and pre-symbolic (maternal-infant) relations to agency, as discussed in the next section.

\section{Some critical reflections: theorising a range of people and things in the subjection of infants}

Butler's attempts to grapple with the subjection of infants can be enhanced via more explicit considerations of a broader range of socio-psychic relations, specifically placing the maternal more centrally. A fuller attention to the maternal helps to theorise inter-dependency, positive accounts of psychic and social relations, and resistance, which complements Butler's (2004) project to unpick relations of recognition and interdependency. In addition, emphasis on the maternal also highlights the importance of emotions and/or affect within accounts of subjection, since maternal-infant relations are conceived of as emotionally (and physically) interdependent. Furthermore, an empirical focus on the specific, everyday, sociospatial contexts of subjection with a consideration of the materiality (of bodies and things), could provide more insight into the range of socio-psychic contexts of infants' socialisation, and contribute to Butler's (2004) and others (Luzia, 2010; Nash, 2005; Oswin, 2010) attempts to reframe socio-psychic relations away from the heterosexist straightjacket of the Oedipus complex and biologically reductive conceptions of origins (Nash, 2012).

Psychoanalytic accounts have been critiqued for unreflectively emerging from western, bourgeois, patriarchical perspectives (Blum and Nast, 1996). It therefore seems paradoxical for Butler $(1997,2004)$ to return to patriarchal and structuralist 
Lacanian or Freudian accounts that suggest the fixity of the symbolic and the primacy of the phallus and the paternal, even as a starting point to critique. Further, like Freud, Butler is in danger of overplaying the sexual and sexuality in psychic development above a more general attention to sensory (but not sexual) pleasures derived from objects and people (breasts, blankets and soft toys (Aitken and Herman, 1997; Winnicott, 1971)). One possible alternative is to focus on maternalinfant (and other) relations and their importance in the emergence of the 'fiction' of an individual in subjection.

There is an increasing strand of feminist scholarship engaging with the maternal within Geography (Gabb, 2004, 2008; Longhurst, 2008; G. Rose, 1996, 2007, Pratt, 2012) and beyond (the establishment of the journal Studies in the Maternal, in 2009). In geography the maternal has also been implicitly present, as a key source of object-relations theories (Bondi, 2005). Some feminists have critiqued attempts to emphasise the maternal, as situating motherhood as the site of femininity or a necessary element of womanhood (Butler, 1990). Of course, I am not proposing that all women should be mothers. Although there have been some recent interesting accounts of mothering and parenting more broadly (Aitken, 2000; Aitken, 2009; Gabb, 2004; Johnson, 2004; Longhurst, 2000; 2001; 2008; Luzia, 2010; Madge and Connor, 2005; Mahon-Daly and Andrews, 2001), these studies also do not suggest that motherhood should be viewed as an essential, universal element of femininity. Here I forward an emphasis on infants' subjection within maternal-infant and other social relations, which has been relatively under-explored. In line with this focus, Söderbäck (2010) stresses:

"All human beings (at least as of yet) have and are born from mothers ... At stake, then, is our own acknowledgement of being born, of having been generated, of springing forth from a dual origin, maternal and paternal (p.10). 
To focus on the maternal, in addition to other potential socio-psychic relations, is to readdress a serious imbalance, since (Post-)Freudian psychoanalytical theory sidelines infant-maternal relations, focusing on those between the (male) infant and the father figure (Ettinger, 2010) ${ }^{v}$. Given the relative neglect of the maternal, there is scope to bring it back in, centrally, to psychoanalytical accounts.

Attending more fully to maternal-infant relations in the development of the subject facilitates theorising sources of resistance and transformation. Like Butler's (1997a) melancholia, Kristeva's (1984) semiotic (the creative, emotional, embodied, beyondrepresentational element of the person which emerges from the infant's relationship with the maternal 'chora'), acts as an unsettling something at the margins of representation, suggesting the edges of, the limits to, acceptable subjectivity. This opens possibilities both for reframing the subject as always constituted interdependently and an entrée into social transformation (Söderbäck, 2010). Bringing the maternal into accounts of infants' psychic and social development does not necessitate relegating other psychic-social relations. As Longhurst (2008) exemplifies, the maternal can be conceptualised as a performed identity positioning that intertwines with corporeal (mothers or motherly) bodies, rather than a fixed attribute of a pre-defined Mother. This sense of a fluid maternal has more scope to consider the myriad possible kinship/social relations of infants.

Söderbäck's (2010) statement, quoted above is problematic. The question remains of the relative importance of biological and social origins, and pre- and post-birth experiences, for instance, for children parented by same-sex partners and/or conceived via reproductive technologies (Hargreaves, 2006). These children are conceived with both ova and sperm and gestated in utero by a woman, certainly, but possibly without any socio-psychic relationship to either a mother or father. Indeed, Butler (2004) is weary of over-emphasising the maternal, since she asserts it 
reinstitutes dyadic relations: "not the phallus, but the maternal, for the two options available are "dad" and "mom" (p.136). However, if the maternal is understood qua Longhurst (2008), as a relational positioning rather than a fixed attribute, incorporating the maternal does not necessitate re-inscribing an infant-mother dyad.

Maternal-infant relationships emphasise psychic (social) processes of 'contact' and 'connection' via 'primary compassion' (Ettinger, 2010: 1), rather than the conflictual development of self-identity in opposition to 'others'vi. These relatively positive psychic relations suggest ways of relating to others which facilitate recognition rather than abjection and projection (Benjamin, 1998; Bondi, 2005). This provides a further potential pathway to social transformation (Butler, 2004). Moreover, these are primarily emotional/affective relationships, which emphasise the foundational importance of emotional relationality to the formation of individuals/subjects.

Approaches that incorporate maternal-infant associations therefore provide scope for a more critical notion of the subject/agent, which is constituted in emotional and physical inter-dependency rather than framed as a holistic subject(ivity) defined in opposition to others (Shildrick, 2010; Irigaray and Wenzel, 1981). This has resonance to Butler's (2004) attempts to reframe subjectivity as ontologically relational, drawing upon Benjamin's (1998) overinclusiveness and Hegel's ek-static concept of the self. Butler's (2004: 136) description of overinclusiveness implicitly emphasises the maternal:

“...a post-oedipal recuperation of overinclusive identification characteristic of the pre-oedipal phase, where identifications with one gender do not entail repudiations of another" (p.136).

Hegel's (1977) ideas of the ek-static self, more fully decentre an autonomous self, suggesting that: 
"the self ... is beyond itself from the start, and defined by this ontological ekstasis [i.e. an enthralled relationship to the Other which takes the self beyond or outside itself, as in religious ecstasies]" (Butler, 2004: 150)

Thus, there is no 'self' that precedes the relationship to the Other or that can be recaptured from the inter-subjectivity between 'Self' and 'Other'; the sense of an autonomous 'individual' belies people's mutual constitution in relationality. These more positive conceptions facilitate an inter-subjective understanding of identity formation (see also Toren, 2009). A recognition of this intersubjectivity at the heart of the formation of the fiction of the individual in infancy and beyond challenges the: "sleight of hand" involved in "the realization of a liberal subject-a wholly individualized fully competent subject" (Ruddick, 2007a: 638), by revealing the complex web of interdependencies through which individuals come into being and are sustained. Deconstructing the sovereign agent facilitates a broadening conception of who is a viable subject and what is a liveable life (Butler, 2004). For instance, children are marginalised by their perceived dependency (Ruddick, 2007b). Such an intersubjective view of the subject/agent is central to Butler's (2004) project. Butler does not fully consider in detail, however, how these overinclusive or ek-static identifications might be played out in infancy.

At the same time as attention to the maternal and other non-paternal socio-psychic relations might provide insight into possibilities of transformation, by focusing upon the intersubjectivity of humans, these relations are also bound up with subjection. Indeed, subjection is arguably most effectively reproduced in nurturing emotional social relations; as Ainsworth (1967), Bowlby (1969) and Winnicott (1965) suggest 'good enough' intersubjective relationships of attachment produce individuals capable of having positive adult social relations and being successful citizens. A 
focus on the maternal does not, then, remove the individual from subjection, but provides new insight into how subjection occurs and how it could be otherwise.

Rather than exclusively focusing upon infant-maternal relations infant geographies could more fully investigate the relationships of infants to a host of human and nonhuman others, providing insight into the potential to be otherwise. For instance, Aitken and Herman (1997), emphasise the role of transitional objects and spaces to Winnicott's $(1965 ; 1971)$ object-relations theories. Transitional objects and spaces are playful and can be re-worked in various ways by children. These objects and spaces do not pre-exist the child's playing with them, but become meaningful in the encounter, and demonstrate, as Aitken and Herman (1997) contend, the becomingness of culture. Importantly, for infants, transitional objects are animate(d) rather than inanimate (Winnicott, 1971).

Shildrick's (2010: 6) conceptualisation of a potential Deleuzian conception of maternity also appeals to such concerns, offering insight into 'productive powers put into play through its [the infant's] interconnections and interactions with an array of others, both organic and non-organic'. Although Deleuze (and Guattari) have little to say about maternity, Shildrick (2010: 10) questions what a Deleuzian approach to maternity might be, and she conceptualises:

"becoming-maternal encompass[ing] all those linked together in the connective tissue that constitutes a more extensive and substantive version of the flesh of the world".

Unsurprisingly, the emphasis is not on 'aboresecent' development that tends towards reproduction of the same. Rather, it is on the: "rhizomatic spread of nodules and connective channels" (p.4), which present the opportunity for ever more 'forms of 
life'. Shildrick (2010: 4) suggests a rhizomatic focus, not on "units - like mother/womb/foetus/infant", but on:

"the mother machine .. reconfigured precisely as a desiring machine, the point of take-off and production in the generation of new life forms and in mobilising new assemblages. The formation of a gamete in vitro, the scan that monitors the foetus in utero, the hand - or instrument - that guides the neonate's head from the birth canal, the infant mouth on the maternal breast, are all nodular moments in the intensifying networks of the desiring mother machine. The rhizomatic spread of such desire is indifferent to any distinction between natural and artificial; it is rather a matter of connections, disjunctions, and transformations" (ibid. p.6-7).

Shildrick's conception offers insight into the possibility of focusing away from individual accounts of maternity towards figuring a more existential ongoingness of life (re)generation, which always has the potential to be otherwise than to follow the self-same patterns of subjection. Her vision has potential to be further developed. Rather than Shildrick's focus on the maternal, it would be possible to take as our starting point another node on the network; that of the infant (see also Brown and Middleton, 2005). Such an approach, focusing upon the vitalism of life presents opportunities for exploring how lives can be otherwise (Greenhough, 2010). The focus on nodes on networks critiques dominant liberal accounts of the subject (Murdock, 1997; Whatmore, 1997, 2002). Perhaps, as critics of Deleuzian accounts and those of Non-Representational Theory have forwarded (Jacobs and Nash, 2003; Tolia-Kelly, 2006), this approach might have less to say about the tendency of entrenched differentiations to endure, rather than to be transformed. Cresswell (2012) also claims that such approaches insufficiently express a specifically human agency (see also Brown and Middleton, 2005). However, Colls (2012) points to potentials of thinking-through sexual and potentially other differences via an 
engagement with such theories and their potential to express the fixity of enduring differentiations within dynamism (Anderson and Harrison, 2010; Saldanha, 2006; cf. Cresswell, 2012). Shildrick (2005) engages with such concerns, considering both the endurance of disability as a category that sets apart and the potential to reanimate bodily difference as a position of radical alterity.

A geographical approach would attend to the contexts of particular places, conceptualised as specific and connected spaces, in how such assemblages come together. As Wood et al. (1994) and others (Holloway, 1998; Oswin, 2010) have demonstrated, the early socialisation sites of infants are not bounded places, but open and connected spaces, dissected by and connected to social, cultural, economic and political processes at a variety of interconnected scales, from the local to the global. Therefore, the socio-spatial contexts of infants' earliest years are important sites in which broader messages, such as about classed, gendered, sexualised, racialised, (dis)abled, religious identities, but also more diffuse and less traceable concerns, are (re)produced. These messages are then incorporated into psyches and help to literally form interconnected and dynamic mind-bodies. Perhaps, however, these mind-bodies are not endlessly dynamic. The attention to the psyche expresses a friction to change. Deeply embedded responses to differences, such as impairment, are not easily transformed (Wilton, 2003). Hence, the importance placed on the contexts of infants' emergence by Butler (2004) and in this paper. In the following section, I consider some possibilities for epistemological and methodological approaches to empirical studies of infants.

\section{Some possible methodological and epistemological approaches to infant geographies}

Research with infants begs important epistemological questions about how we can seek knowledge about their lives, given, to date, geographers have neglected to 
explore infants' worlds. Infants do not communicate verbally. Most babies' main form of communication is to cry, and parents/carers have to deduce what they want. As infants age, the range of their communication diversifies; they start to develop different cries, they smile, they laugh, they point and wave (and can be taught other signs), they begin to vocalize (babble) and form word-sounds (Stern, 2006).

The inclusion of non-verbal actors, such as infants, in research contributes to ongoing methodological attempts to move away from the idea of the speaking, sovereign, rationally reflective agent, which continues to implicitly frame much social science research (see Davies and Dwyer, 2007; Lorimer, 2005, 2007, 2008). Engaging with the lives of infants and babies ties into broader methodological endeavours to unravel aspects of everyday life that are difficult to represent in established modernist frames of reference, such as the emotional and 'affective' (Bondi, 2003; Merchant, 2011; Pile, 2010; Smith et al., 2009) and/or research with non-verbal (in human terms) actors, such as animals (Laurier et al., 2006; Lewis, 2001; Nosworthy, 2010; Philo and Wilbert, 2000; 2009, 2010).

I would suggest that a relatively inductive ethnographic approach would be appropriate to apprehending the becoming of infants within constellations of human/non-human others in specific spaces. Ethnographic approaches to studying infants could draw upon three main traditions, which are briefly elucidated here: first, geographical accounts of Non-Representational Theory, emotions and Affect; second, infant observational studies; and third, the limited existent geographical research on parenting infants and the everyday geographies of young children.

There is a bourgeoning ethnographic tradition within geographical concerns which seek to engage with the experiences of non-verbal actors and/or studies which attempt to unravel emotion, affect and other aspects of life which are difficult to 
express with recourse to cognitive knowledges and verbal or written expression (Harker, 2005; Loughenbury, 2009; Morton, 2005; Nosworthy, 2009, 2010; Parr, 1998; Revill, 2004; Woodyer, 2008). Ethnographic approaches are particularly open to challenging the liberal subject/agent, by facilitating a focus upon interconnections between things and people in specific spatial contexts and within the present moment.

Although discussions of ethnography which engage with Non-Representational Theory tend to depict a break with previous approaches, there is an underacknowledged continuity with ethnographic traditions, particularly within feminist and/or children's geographies (Hart, 1979; Katz, 2004). Woodyer (2008), whilst retrieving this hidden history, suggests a shift from a sense of engagement with an already existing world towards 'performance' where ethnographers are co-present and transformative within the world, which only comes into being within specific events. There is a move towards engaging more fully with a processual sense of the relational, embodied and material becomingness of specific ethnographic encounters, rather than a static representation of things 'as they are' (Woodyer, 2008). Perhaps this epistemological break is overstated (for instance, similar concerns can be unpicked within feminist approaches to ethnography - see in particular Katz's (2004) work on mimesis). However, this focus on process rather than stasis, embodied and emotional engagement above distanced observation, and performance, are useful tools for exploring the worlds of infants in non-reductive ways. Innovative methods, such as visual methods - photography, videoing and so on, are also often used in exploring the beyond-representational (Simpson, 2011), with children (Thompson, 2008), and have been used to untangle familial relationships and settings (Rose, 2004, 2010). Often, visual methods are an aspect of a broader ethnographic approach (Rose, 2007; Pink, 2007), and these methods too could be appropriate to geographies of infants. 
In searching for ways of apprehending infants' lives, geographers could engage with existing research with infants and young children outwith geography. The majority of studies of early childhood draw upon quantitative, deductive, psychological approaches (for instance Journal of Early Childhood Research, Early Childhood Research Quarterly; Benson and Haith, 2009). Nonetheless, qualitative infant observations (particularly of infant-carer interactions) have a long history and are currently bourgeoning. These have potential insights to offer geographies of infants. Different, inter-related traditions infant observation have been pioneered by Mary Ainsworth (1967) Esther Bick (1964), Anna Freud (1954), and Melanie Klein (1997a) and further developed by Daniel Stern (Stern, 2006).

There is increasing recognition of the contribution of infant observation to developmental psychology, child psychotherapy and sociology research, along with its long-established role in psychoanalytical training (Biggs, 2002; Edmiston, 2008; Journal of Infant Observation, established 1997). There is, of course, a heterogeneity of approaches within Infant Observation, ranging from the relatively structured (Freud, 1954; Bick, 1964) to the unstructured (Klein, 1997), with the focus on differing ideas of psychic and psychological development, from mother-baby attachment (although the potentials for exploring diverse attachments are immense, McHale, 2007) to the internal development of the psyche. Klauber (2012) suggests that psychoanalytical theory emphasises how social relationships are internalised within the psyche, whereas attachment theory considers more fully the empirical contexts of children's everyday lives $^{\text {vii }}$ (see Stern, 2006 for an approach that synthesises both perspectives and Blum and Secor, 2011 for an attempt to integrate psychic and material space). 
I argue that more unstructured observation could provide the in-depth, lively ethnographies envisaged here. An example is Stern's (2006: iv) "narrative approach to the non-verbal"). Daniel Stern's (2006) work has much to offer geographies of infants, although there might be elements to critique. His dialogue between development psychology, attachment theory and psychoanalytical theory has enabled him to move away from staged processes of development, towards a 'layered model of development' in which, contra Freud and Piaget, various phases of infant 'development' co-exist rather than one phase completely replacing another. The critique levelled at this model for being a "model of growth, not development" (ibid.: xiii) might appeal to geographers who have been critical of developmental approaches to childhood. His exploration of infants' social worlds, including human and non-human relations are also of interest. Stern's insistence on a different cognitive relationship to the human and non-human would be less palatable. His focus on an already differentiated self is also somewhat troubling to attempts to reconfigure the subject/agent as inherently intersubjective. However, his suggestion that the primary task of infants is not to construct differentiations between 'same' and 'other', but to forge connections is useful, as is his focus on "ways of being with" (p.xxvii) as opposed to psychic internalisation. Stern's insistence on children as active participants in their development would appeal to geographers' concerns to not view subjection as something done to infants, but as a process in which they actively engage. His adoption of an embodied view of the mind also addresses enduring concerns within geography to critique the mind-body dualism (Parr and Butler, 1999). He is also interested in issues of affect and porous body boundaries, considering intersubjectivity to begin at birth or shortly after and paying attention to people's ability to affect others' neurology. His later interest in momentary and fleeting interactions would also appeal to geographers (Stern, 2004). Despite all of these potential overlaps, Stern (2006) displays a tendency towards chronological 
sequencing, much less evident than in his developmental psychologist peers, but present nevertheless.

The excerpt below gives a sense of the kinds of in-depth observation emerging from the contemporary field of childhood observation studies:

Julia at 23 days

People were arriving and, even when Lesley greeted them, Julia kept her eyes fixed on her mother. A young boy came over and looked at Julia, commenting on how small she was. After some minutes of bustle, Lesley began to nurse Julia again. In a very short while, she looked at me and mouthed that she was asleep. But a few minutes later Julia woke up and began to hiccup. Lesley patted her on her back and then tried holding her in her arms with her hand in front of her face. The hiccups persisted (Sowa and Faccino, 2010: 229).

Geographers could contribute to the field, for instance by placing a greater emphasis on the material spatialities of infants' lives and how the emergence of infant subjectivities occurs (differently) within particular spatial contexts, in relation to a host of 'others' and in specific constellations of powers and resources. Current studies are relatively devoid of such considerations, and too often reproduce ethnocentric and classed ideals of parenting (focusing on and implicitly 'othering' not-good-enough usually working class or socially excluded mothers, Jensen, 2010). There are many lessons to be learned about how gender, race/ethnicity, sexuality, class and so on are (re)produced differently via infants' emerging subjectivities in various social and kinship contexts.

Important insights can be gained from the limited number of ethnographic geographical studies that have attempted to grapple with issues of maternity, birthing 
and parenting of infants (Aitken, 2000; Gabb, 2004; Longhurst, 2008). The focus could be more squarely on the subjection of, and the lives of, infants. It is important that the agency of infants themselves come to the fore in such accounts, so that infants are witnessed as active participants in processes of subjection. Clearly, infants are not envisaged as fully rational or autonomous agents (see also Brown and Middleton, 2005). Indeed, the very (inter)dependent nature of infancy brings into sharp relief the fiction of the sovereign agent.

Ethnographic explorations of young children offer insight into how the agency of children can be expressed without recourse to a notion of a sovereign, autonomous agent (Hancock and Gillen, 2007; cf. Horton and Kraftl 2011) viii. An extract from Gallacher (2005: 255) gives a sense of the rich insight that such approaches provide:

"Blair, Liam and Logan were in the music corner climbing on the empty book bench. SARAH told them not to climb because it is dangerous. They ignored her and continued climbing. SARAH lifted them off the bench and told them to go and play with the toys. Liam and Logan went off to find something else to do but Blair stayed behind and started to climb again. SARAH warned him, I'm watching you. I'm watching you closely Blair Scott!' He continued to climb for a moment but decided against it and went off to play somewhere else".

Gallacher's (2005) insightful study of power-relations among two year olds and nursery workers could be taken forward via a livelier encounter with people and things and a more thorough consideration of subjection; how do these processes of domination and resistance generate specifically gendered, racialised, classed, subjects? What insight do these contexts of young children's subjection offer for how things could be played out otherwise? Of course, the expectation in this paper is that the children who are the focus of the research are even younger than those in Gallacher's study. 
Whichever methodological approaches are used, certain ethical issues arise in the study of infants. First, it remains pertinent to question to what extent adult researchers can apprehend the life-worlds of infants. Representing infants' lives involves interpreting their everyday practices within adult discursive frameworks, which are, presumably, meaningless to infants. How, then, can ventriloquism, which could be used to stake the 'claims' of infants against those of parents and others (Ruddick, 2007a), be avoided? Parents, carers, siblings and others could be involved in projects about infants, with researchers drawing upon their interpretations along with those of the researcher (e.g. Stern's (2004) microanalytic interview in which momentary events are explored in minute detail; see also Hall and Kearns (2001)). This is not to suggest that parents can be infants' proxies; any attempt at representation is limited and framed; parents, siblings and others are no more or less fallible than researchers (Rose, 1997).

Second, conducting research with infants raises ethical problems that cannot be overcome by the standard ethical repertoires by which human geographers are regulated (Librett and Perone, 2010; Dyer and Demerrit, 2009). Within children's geographies, it is widely accepted that children can and should 'consent' to research (Alderson and Morrow, 2004; Holt, 2004; Valentine, 1999). However, the concept of gaining active consent assumes a knowing and speaking agent, which paradoxically, marginalises children (Ruddick, 2007a, b). Many groups who cannot attain the status of a cognisant, speaking actor to consent are thus excluded from research (Butz, 2008). Researchers of young and/or disabled children have re-cast the issue of consent as an ongoing interpretive and reflexive process of assent (Cocks, 2006). This has resonance to endeavours in human geography to reconfigure ethics outside of the box of representational frameworks and beyond the sovereign subject/agent (Bondi, 2003; Greenhough and Roe, 2011; Parr, 1998; Pile, 1991; Whatmore, 1997). 


\section{Conclusion}

This paper has illuminated the importance of investigating the subjection of infants, taking a lead from Butler's $(1997 a, 2004)$ casting of infancy as crucial to both the incorporation of power within/as psyches, which produces a fictional sense of an internal and socially anterior self, and how subjection could occur otherwise within different sets of social relations. The specific contexts of infants' emergence are of particular interest to exploring the nature of subjection, and how enduring inequalities are reproduced via embodied identities and how social transformation could proceed; messages circulating in early childhood are foundational to the formation of the psyche, pre-discursive and, although they are dynamic, they are not infinitely so, and express a friction to change. A focus on infancy also highlights more generally how the formation of 'subjects' with their imminent agency is predicated on emotional and physical interdependencies, which is a broader enduring concern to both Butler's and human geography. Highlighting the emotional inter-subjectivity of the formation of apparently bounded and rational subjects has resonance for geographies of emotion and Affect.

A critical reading of Butler has suggested a need to explore, empirically, a diversity of social relations of subjection which takes fuller account of the maternal along with a host of infant (human and non-human) other relations. The material co-presence of non-human others is particularly pertinent since 'inanimate' objects play an important role in young children's psychic development (Aitken and Herman, 1997; Winnicott, 1971). Drawing upon literature from infant observation studies, and human geography (particularly those which have engaged with non-representational theory, early childhood and/or parenting infants), I have suggested that studies of infant geographies could be lively ethnographies. However, concerns about ventriloquizing 
infants might be minimalized by also researching with parents, siblings, and others who are part of an individual infants' subjection network.

\section{$\underline{\text { References }}$}

Ainsworth MDS, 1967 Infancy in Uganda: Infant care and the growth of love (Johns Hopkins University Press, Baltimore)

Aitken SC, Herman T, 1997, "Gender, power and crib geography: transitional spaces and potential places" Gender, Place and Culture 463 - 88

Aitken SC, 2000, "Fathering and faltering: "Sorry, but you don't have the necessary accoutrements" Environment and Planning A 32581 - 598

Aitken SC, 2009 The Awkward Spaces of Fathering (Ashgate, Aldershot)

Alderson P, Morrow V, 2004 Ethics, Social Research and Consulting with Children and Young People (Barkingside: Banardos).

Anderson B and Harrison P, 2010, "The promise of non-representational theories", in Taking-Place: Non-Representational Theories and Geography Eds B Anderson and

P Harrison (Ashgate, Aldershot) pp 1-34

Barglow P, Vaughn BE, Molitor N, 1987, "Effects of maternal absence due to employment on the quality of infant - mother attachment in a low - risk sample" Child Development 58945 - 54

Benjamin J, 1998 The Shadow of the Other: Intersubjectivity and Gender in Psychoanalysis (Routledge, New York)

Bick E, 1964, "Notes on infant observation in psychoanalytic training" International Journal of Psychoanalysis 45558 - 566.

Blum V and Secor A, 2011, "Psychotopologies: closing the circuit between psychic and material space" Environment and Planning D: Society and Space 29 1030-1047

Blum V, Nast H, 1996, "Where is the difference? The heterosexualisation of alterity in Henri Lefebvre and Jacques Lacan" Environment and Planning D: Society and Space 14559 - 580

Bondi L, 2005, "Making connections and thinking through emotions; between geography and psychotherapy" Transactions of the Institute of British Geographers $30433-48$

Bourdieu P, Thompson JB, 1991, Language and Symbolic Power (Harvard University Press, Cambridge MA)

Bowlby J, 1969 Attachment and Loss Vol 1 (Basic Books, New York)

Brown SD and Middleton D, 2005, "The baby as virtual object: agency and difference in a neonatal intensive care unit" Environment and Planning D: Society and Space 23 695-715

Butler J 2004 Undoing Gender (Routledge, London/New York)

Butler J, 1990 Gender Trouble: Feminism and the Subversion of Identity (Routledge, New York) 
Butler J, 1997a The Psychic Life of Power: Theories in Subjection (Stanford University Press, Stanford)

Butler J, 1997b Excitable Speech: The Politics of the Performative (Routledge, New York)

Butler J, 2000 Antigone's Claim: Kinship between Life and Death (Columbia University Press, New York)

Butz D, 2008, "Sidelined by the guidelines: reflections on the limitations of standard informed consent procedures for the conduct of ethical research" ACME: An International E-Journal for Critical Geographies 7 239-259

Callard F, 2003, "The taming of psychoanalysis in geography" Social and Cultural Geography 4 295-312.

Cocks AJ, 2006, "The Ethical Maze: finding an inclusive path toward gaining children's agreement to research participation” Childhood 13247 - 266

Colls R, 2012, "Feminism, bodily difference and non-representational geographies" Transactions of the Institute of British Geographers 37 430-455

Cresswell T, 2012, "Review essay. Nonrepresentational theory and me: notes of an interested sceptic" Environment and Planning D: Society and Space 3096 -105

Davies G, 2012, "Caring for the multiple and the multitude: assembling animal welfare and enabling ethical critique" Environment and Planning D: Society and Space advance online doi:10.1068/d3211

Davies G, Dwyer C, 2007, "Qualitative methods: are you enchanted or are you alienated?" Progress in Human Geography 31257 - 266

Davies G, Dwyer C, 2008, "Qualitative methods II: minding the gap" Progress in Human Geography 32399 - 406

Dyer S, Demeritt D, 2009, "Un - ethical review? Why it is wrong to apply the medical model of research governance to human geography" Progress in Human Geography $3146-64$

Edmiston B, 2008 Forming Ethical Identities in Early Childhood Play (Routledge, London).

Ettinger B, 2010 “(M)Other re - spect: maternal subjectivity, the ready - made mother - monster and the ethics of respecting" Studies in the Maternal 2 www.mamsie.bbk.ac.uk

Foucault M, 1978 The History of Sexuality: An Introduction (Pantheon Books, New York)

Freud A, 1954, "Some remarks on infant observation" Psychoanalytical Study of the Child $89-19$

Gabb J, 2004, "I could eat my baby to bits': passion and desire in lesbian mother children love" Gender, Place and Culture 11399 - 416

Gallacher LA, 2005, "'The Terrible Twos': Gaining control in the nursery?" Children's Geographies 3243 - 264

Gallagher M, 2011, "Sound, space and power in a primary school" Social and Cultural Geography 12 47-61 
Greenhough B and Roe EJ, 2011, "Ethics, space, and somatic sensibilities: comparing relationships between scientific researchers and their human and animal experimental subjects" Environment and Planning D: Society and Space 29 47-66

Greenhough B, 2010, "Vitalist geographies: Life and the more-than-human", in Taking Place: Non-Representational Theories and Geography Eds B Anderson and $P$ Harrison (Ashgate, Farnham) pp 37-54

Gregson N and Rose G, 2000, "Taking Butler elsewhere: performativities, spatialities and subjectivities" Environment and Planning D: Society and Space 18 433-452

Hall E, Kearns R, 2001, "Making space for the 'intellectual' in geographies of disability" Health and Place 7237 - 246

Hancock R, Gillen J, 2007, "Safe places in domestic spaces: two - year - olds at play in their homes" Children's Geographies 5337 - 351

Hansen $\mathrm{N}$ and Philo C, 2007, "The normality of doing things differently: bodies, spaces and disability geography" Tijdschrift Voor Economische En Sociale Geografie 98 493-506

Hargreaves K, 2006, "Constructing families and kinship through donor insemination" Sociology of Health and IIIness 28 261-283

Harker C, 2005, "Playing and affective time-spaces" Children's Geographies 3 47-62

Harrison LJ, Ungerer, J A, 2002, "Maternal employment and infant - mother attachment security at 12 months postpartum" Developmental Psychology, 38(758 773

Harrison P, 2008, "Corporeal remains: vulnerability, proximity, and living on after the end of the world" Environment and Planning A 40423 - 445

Hart R, 1979 Children's Experience of Place (Halsted Press, New York)

Holloway SL, 1998, "Local childcare cultures: moral geographies of mothering and the social organisation of pre - school education" Gender, Place and Culture 529 53

Hollway W, 2006, "Family figures in 20th - Century British 'psy' discourses" Theory and Psychology $16443-464$

Holt L, 2004, "The 'voices' of children: de-centring empowering research relations" Children's Geographies 213 - 27

Holt L, Lea JA and Bowlby S, forthcoming, "Alternative spaces of education for young people with socio-emotional differences in mainstream schools: sites of alternative social expression or extending the reach of normalisation?" Environment and Planning A

Horton J, Kraftl P, 2011, "Tears and laughter at a Sure Start Centre: toddlers' geographies, policy contexts", in Geographies of Children, Youth and Families: International Perspectives L Holt ed (Routledge, London) pp235 - 249

Irigaray L and Wenzel HV, 1981, "And the one doesn't stir without the other" Signs 7 $60-67$

Jacobs JM and Nash C, 2003, "Too little, too much: cultural feminist geographies" Gender, Place and Culture: A Journal of Feminist Geography 10 265-279 
Jensen T, 2010, "Warmth and wealth: re - imagining social class in taxonomies of good parenting" Studies in the Maternal 2 www.mamsie.bbk.ac.uk

Johnson R, 2004, "Bars, breasts, babies: justice L'Heureux - Dubé and the boundaries of belonging", in Adding Feminism to Law: the Contributions of Justice Claire L'Heureux - Dubé, (Irwin, Chicago) pp 139 - 157

Katz C, 2004 Growing Up Global: Economic Restructuring and Children's Everyday Lives (Univ of Minnesota Press, Minneapolis, MN)

Klein M, 1997 Envy and Gratitude and Other Works 1946-1963 (Vintage, London)

Laurier E, Maze R, Lundin J, 2006, "Putting the dog back in the park: animal and human mind - inaction" Mind, Culture and Activity 13 2-24.

Lewis M, 2001, Learning to Listen: Consulting Children and Young People with Disabilities (Save the Children, London)

Librett M, Perrone D, 2010, "Apples and orange: ethnography and the IRB" Qualitative Research 10729 - 747

Longhurst R, 2000, "'Corporeographies' of pregnancy: 'bikini babes'" Environment and Planning D: Society and Space 18453 - 472

Longhurst R, 2006, "A pornography of birth: crossing moral boundaries" ACME: An International E - Journal for Critical Geographies 5209 - 229

Longhurst R, 2008 Maternities: Gender, Bodies and Space (Routledge, London / New York)

Longhurst, R 2001 Bodies: Exploring Fluid Boundaries (Routlege, London)

Lorimer H, 2005, "Cultural geography: the busyness of being 'more - than representational" Progress in Human Geography 2983 - 94

Lorimer H, 2007, "Cultural geography: worldly shapes, differently arranged" Progress in Human Geography 3189 - 100

Lorimer H, 2008, "Cultural geography: nonrepresentational conditions and concerns" Progress in Human Geography 32551 - 9

Loughenbury R, 2009, "Ethnomethodology and the non - representational: what are disaffected young white men capable of?" Geography Compass 3 1408-1429

Luzia K, 2010, "Travelling in your backyard: the unfamiliar places of parenting" Social and Cultural Geography 11 359-375

Madge C, O'Connor H, 2005, "Mothers in the making? Exploring notations of liminality in hybrid cyber/space" Transactions of the Institute of British Geographers 3083 - 97

Mahon-Daly P, Andrews GJ, 2001, "Liminality and breastfeedling: women negotiating two bodies" Health and Place 861 - 76

McDowell L, 2006, "Reconfigurations of gender and class relations: class differences, class condescension and the changing place of class relations" Antipode 38825 850

McHale JP, 2007, "When infants grow up in multiperson relationship systems" Infant Mental Health Journal 28, 370 - 92

McNay L, 1999, "Subject, psyche and agency" Theory, Culture and Society 16 175193 
McNay L, 2004, "Agency and experience: gender as a lived relation" The Sociological Review 52 173-190

Merchant S, 2011, "The body and the senses: visual methods, videography and the submarine sensorium" Body and Society 1753 - 72

Mitchell J, 2006, "The sibling and the other" Publicalia of Division 39, APA, USA

Morton F, 2005 "Performing Ethnography: Irish traditional music sessions and new methodological spaces" Social and Cultural Geography 6661 - 676

Murdoch J, 1997, "Inhuman/nonhuman/human: actor-network theory and the prospects for a nondualistic and symmetrical perspective on nature and society" Environment and Planning D: Society and Space 15 731-756

Nash C, 2005, "Geographies of relatedness" Transactions of the Institute of British Geographers 30449 - 462

Nash C, 2011, "Genetics, race, and relatedness: human mobility and human diversity in the Genographic project" Annals of the Association of American Geographers 102 667-684

Nast H, 2000, "Mapping the "unconscious": racism and the oedipal family" Annals of the Association of American Geographers 90215 - 255

Nelson L, 1999, "Bodies (and spaces) do matter: the limits of performativity" Gender, Place and Culture: A Journal of Feminist Geography 6 331-353

Nosworthy C, 2010 A Geography of Horse - Riding: The Spacing of Affect, Emotion and (Dis)ability Identity Through Horse - Human Encounters" PhD thesis, Department of Geography, University of Reading, UK

Oswin N, 2010, "The modern model family at home in Singapore: a queer geography" Transactions of the Institute of British Geographers 35 256-268

Parr H and Butler R, 1999, "New geographies of illness, impairment and disability", in Mind and Body Spaces: Geographies of IIIness, Impairment and Disability Eds R Butler and H Parr (Routledge, London) pp 1-24

Parr H, 1998, "The politics of methodology in 'post - medical geography': mental health research and the interview" Health and Place 4341 - 353.

Parr H, Davidson J, 2011, "Psychic life", in A Companion to Cultural Geography Eds VJ Del Casino Jnr, ME Thomas, P Cloke, R Panelli (Wiley - Blackwell, Chichester, UK) pp 275 - 292

Philo C, Parr H, 2003, "Introducing psychoanalytic geographies" Social and Cultural Geography 4283 -293

Philo C, Wilbert C., Eds, 2000 Animal Spaces, Beastly Places (Routledge, London)

Pile S, 1991, "Practising interpretative human geography" Transactions of the Institute of British Geographers 16 458-69

Pile S, 1996 The Body and the City: Psychoanalysis, Space and Subjectivity (Routledge, London)

Pile S, 1997, "Oppression, political identities and spaces of resistance" in Geographies of Resistance Eds M Keith, S Pile (Routledge, London/New York) pp 132 
Pile S, 2010, "Emotions and affect in recent human geography" Transactions of the Institute of British Geographers 355 - 20

Pink S, 2007 Doing Visual Ethnography: Images, Media and Representation in Research (Sage Publications Ltd, Thousand Oaks, CA)

Pratt G, 2012 Families Apart: Migrant Mothers and the Conflicts of Labor and Love (University of Minnesota Press, Minneapolis, MN)

Revill G, 2004, "Cultural geographies in practice Performing French folk music: dance, authenticity and nonrepresentational theory" Cultural Geographies 11 199209

Rose G, 1996, "As if the mirrors had beld: Masculine dwelling, masculinist theory and feminist masquerade" in BodySpace: Destabilizing Geographies of Gender and Sexuality Ed N Duncan (London, Routledge) pp 56 - 74

Rose G, 1997, "Situating knowledges: positionality, reflexivities and other tactics" Progress in Human Geography 21305 - 320

Rose G, 2004, “'Everyone's cuddled up and it just looks really nice': an emotional geography of some mums and their family photos" Social and Cultural Geography 5 $549-564$

Rose G, 2007 Visual Methodologies (Sage, London)

Rose G, 2010 Doing Family Photography: The Domestic, The Public and the Politics of Sentiment (Ashgate, Aldershot)

Rose M, 2002, "The seductions of resistance: power, politics, and a performative style of systems" Environment and Planning D: Society and Space 20 383-400

Ruddick S, 2007a, "At the horizons of the subject: part one" Gender, Place and Culture 14513 - 526

Ruddick S, 2007b, "At the horizons of the subject: part two" Gender, Place and Culture 14627 - 240

Saldanha A, 2006, "Reontologising race: the machinic geography of phenotype" Environment and Planning D: Society and Space 24 9-24

Shildrick M, 2005, "Transgressing the law with Foucault and Derrida: some reflections on anomalous embodiment" Critical Quarterly 47 30-46

Shildrick M, 2010, "Becoming-maternal: Things to do with Deleuze" Studies in the Maternal 2, http://www.mamsie.bbk.ac.uk/back issues/issue three/shildrick.html

Shilling C, 2003 The Body and Social Theory (Sage, London)

Sibley D 1995, Geographies of Exclusion: Society and Difference in the West (Routledge, London)

Simpson P, 2011, "So, as you can see ... .': some reflections on the utility of video methodologies in the study of embodied practices" Area 43 DOI: 10.1111/j.1475 4762.2011.00998 (early view)

Smith M, Davidson J, Cameron L, Bondi L, 2009, "Introduction: geography and emotion - emerging constellations", in Emotion, Place and Culture Eds M Smith, J Davidson, L Cameron, L Bondi (Ashgate, Aldershot) 
Söderbäck F, 2010, "Motherhood: a site of repression or liberation? Kristeva and Butler on the maternal body" Studies in the Maternal 2 www.mamsie.bbk.ac.uk

Stern DN, 2004 The Present Moment in Psychotherapy and Everyday Life (Norton, New York)

Stern DN, 2006 The Interpersonal World of the Infant: A View from Psychoanalysis and Developmental Psychology (Basic Books, New York)

Thomas ME, 2007, "The implications of psychoanalysis for qualitative methodology: the case of interviews and narrative data analysis" The Professional Geographer 59 537-546.

Thompson P, 2008 Ed Doing Visual Research with Children (Routledge, London)

Tolia-Kelly DP, 2006, "Affect-an ethnocentric encounter? Exploring the 'universalist' imperative of emotional/affectual geographies" Area 38 213-217

Toren C, 2009, "Intersubjectivity as epistemology" Social Analysis 53 130-146

Valentine G, 1999, "Being seen and heard? Ethical dilemmas of research with children and young people" Journal of Ethics, Place and Environment 2 141-155

Werner JS, 2006, "Between memory and desire: gender and the remembrance of war in doi moi Vietnam" Gender, Place and Culture 13 303-315

Whatmore S, 1997, "Dissecting the autonomous self: hybrid cartographies for a relational ethics" Environment and Planning D: Society and Space 15 37-53

Whatmore S, 2002 Hybrid Geographies: Natures, Cultures, Spaces (Sage, Thousand Oaks, Ca.).

Wilton RD, 2003, "Locating physical disability in Freudian and Lacanian psychoanalysis: problems and prospects" Social and Cultural Geography 4369 - 389

Winnicott DW, 1965 The Family and Individual Development (Routledge, London)

Winnicott DW, 1971 Playing and Reality (Routledge, London)

Wood D, Beck RJ and Wood I, 1994 Home Rules (Johns Hopkins University Press, Baltimore MD)

Woodyer T, 2008 "The body as research tool: embodied practice and children's geographies" Children's Geographies 6349 - 362

\footnotetext{
'This paper focus upon the geographies of infants, taken from psychoanalytical accounts as children under two years old (Stern, 2006).

ii I use the term individual throughout. This is not to suggest that I use the term to describe an autonomous and bounded subject/agent. By contrast, I consider how the fiction of a bounded 'individual' is socio-spatially constructed within specific interdependent relations within western contexts. However, although it is possible to critique and unpack the term 'individual' or 'individual identity', this does not preclude the use of the term. As Butler (2004: 178-9) suggests "If one calls such terms into question, does it mean that they cannot be used anymore? Does it mean that one is now prohibited from such a term by the superego of theoretical postmodernism or that they are proclaimed as exhausted and finished? Or is it simply that the terms do not function in quite the same way as they once did?"
} 
iii Of course, power does not operate exclusively along these traditional lines of dissection. See Colls (2012) for a discussion of the more nebulous differentiations and connections between bodies.

iv While also the title of her 1997 book, I use the term to explore Butler's sustained engagement with how power operates psychically, in the formation of individuals, in ways that are difficult to trace.

${ }^{v}$ This has not been the case in psychoanalytical geographies, where the focus has been on object-relations theories which more fully engage with maternal-infant relations. However, overall these have not investigated the geographies of infants (cf. Aitken and Herman, 1997). vi This is not to suggest that all social relationships between mothers and infants, rather psychoanalytical accounts of infant-maternal relations redress the balance towards attachment and connection.

vii Critiques can be levelled at Bowlby's attachment theory (see Hollway, 2006). For instance, this work has been used to suggest that women should be the primary care givers of young children (Barglow et al., 1987). It is, however, possible to broaden conceptions of attachment to a variety of caregivers and familial contexts (McHale, 2007; Mitchell, 2006). There is no necessary association of attachment theory with conservative views (Harrison and Ungerer, 2002).

viii Geographical research about young children draws upon a broader, although still limited, field of qualitative studies in anthropology and sociology about early childhood (e.g. Brorson, 2005; Edmiston, 2008). 